\title{
Improving robustness and accuracy of predicted daily methane emissions of dairy cows using milk mid-infrared spectra
}

Short title: Improving milk spectra predictions of methane emissions

\section{Amélie Vanlierde a, Frédéric Dehareng a*, Nicolas Gengler b ${ }^{\text {, Eric Froidmont }}{ }^{\mathrm{c}}$, Sinead McParland d, Michael Kreuzer ${ }^{\text {e }}$, Matthew Bell f1, Peter Lund g, Cécile Martin ${ }^{\text {h }}$, Björn Kuhla $^{i}$ and Hélène Soyeurt ${ }^{b}$}

${ }^{\text {a }}$ Walloon Agricultural Research Centre, Valorization of Agricultural Products, 5030 Gembloux, Belgium

${ }^{\mathrm{b}}$ Gembloux Agro-Bio Tech - University of Liège, AGROBIOCHEM Department and Research and Teaching Centre (TERRA), 5030 Gembloux, Belgium

${ }^{c}$ Walloon Agricultural Research Centre, Production and Sectors Department, 5030 Gembloux, Belgium

d Teagasc, Animal and Grassland Research and Innovation Centre, Moorepark, Fermoy, Co. Cork, Ireland

e ETH Zürich, Institute of Agricultural Sciences, 8092 Zürich, Switzerland

f Agri-Food and Biosciences Institute (AFBI), Large Park, Hillsborough, BT26 6DR, United Kingdom

g Aarhus University, Department of Animal Science, AU Foulum, 8830 Tjele, Denmark

${ }^{\text {h }}$ Université Clermont Auvergne, INRA, VetAgro Sup, UMR Herbivores, F-63122 SaintGenès-Champanelle, France

${ }^{i}$ Leibniz Institute for Farm Animal Biology (FBN), Institute of Nutritional Physiology, 18196 Dummerstorf, Germany

This article has been accepted for publication and undergone full peer review but has not been through the copyediting, typesetting, pagination and proofreading process which may lead to differences between this version and the Version of Record. Please cite this article as doi: 10.1002/jsfa.10969 
*Corresponding Author 


\section{ABSTRACT}

\section{BACKGROUND}

A robust proxy for estimating methane $\left(\mathrm{CH}_{4}\right)$ emissions of individual dairy cows would be valuable especially for selective breeding. This study aimed to improve the robustness and accuracy of prediction models that estimate daily $\mathrm{CH}_{4}$ emissions from milk Fourier-transform mid-infrared (FT-MIR) spectra by 1) increasing the reference dataset and 2) adjusting for routinely recorded phenotypic information. Prediction equations for $\mathrm{CH}_{4}$ were developed using a combined dataset including daily $\mathrm{CH}_{4}$ measurements ( $\mathrm{n}=1,089$; g/day) collected using the $\mathrm{SF}_{6}$ tracer technique $(\mathrm{n}=513)$ and measurements using the respiration chambers $(\mathrm{RC}, \mathrm{n}=576)$. Furthermore, in addition to the milk FT-MIR spectra, the variables of milk yield (MY) on the test day, parity (P) and breed (B) of cows were included in the regression analysis as explanatory variables.

\section{RESULTS}

Models developed based on a combined $\mathrm{RC}$ and $\mathrm{SF}_{6}$ dataset predicted the expected pattern in $\mathrm{CH}_{4}$ values (in g/day) during a lactation cycle, namely an increase during the first weeks after calving followed by a gradual decrease until the end of lactation. The model including MY, $\mathrm{P}$ and $\mathrm{B}$ information provided the best prediction results (cross-validation statistics: $\mathrm{R}^{2}=0.68$ and standard error $=57 \mathrm{~g} \mathrm{CH}_{4} /$ day).

\section{CONCLUSIONS}

The models developed accounted for more of the observed variability in $\mathrm{CH}_{4}$ emissions than previously developed models and thus were considered more robust. This approach is suitable for large-scale studies (e.g. animal genetic evaluation) where robustness is paramount for accurate predictions across a range of animal conditions.

Key Words: methane, milk, MIR spectra, dairy, phenotype, reference method 


\section{INTRODUCTION}

Estimation of individual methane $\left(\mathbf{C H}_{4}\right)$ emissions from a large number of animals and development of strategies to reduce such emissions represent major challenges for the dairy sector. Indeed, $\mathrm{CH}_{4}$ has a global warming potential 28 times that of carbon dioxide ${ }^{1}$. Livestock sector represents at global level 14.5\% of human-induced greenhouse gases (GHG) where emissions of enteric $\mathrm{CH}_{4}$ contribute to $39 \%{ }^{2}$.

Measuring individual daily $\mathrm{CH}_{4}$ emissions (g/day) using the classical reference techniques (i.e., respiration chamber, $\mathrm{SF}_{6}$ tracer gas technique) is labor intensive and expensive. These techniques are typically applied in research scenarios and are not feasible for large-scale studies, such as for the purpose of genetic selection where thousands of data records are needed ${ }^{3}$. So, a robust proxy to estimate $\mathrm{CH}_{4}$ would be valuable.

Previous studies highlighted the use of milk components such as fatty acids to estimate enteric $\mathrm{CH}_{4}$ emissions ${ }^{4,5,6}$, suggesting an indirect link between $\mathrm{CH}_{4}$ emissions and milk composition. Furthermore, previous investigations ${ }^{7,8,9}$ have shown that the milk Fouriertransform mid-infrared (FT-MIR) spectra can be a convenient proxy for daily enteric $\mathrm{CH}_{4}$ emissions, as the analysis of milk samples can be performed quickly and at reasonable cost. Indeed, individual milk FT-MIR spectra are already collected routinely during the milk recording process and thus present a potential solution for estimating individual $\mathrm{CH}_{4}$ emissions during a day on a large number of cows maintained under commercial conditions ${ }^{10}$, 11, 12. This prospect is particularly interesting for large-scale studies such as those needed for genetic selection ${ }^{3,13,14,15}$ or for benchmarking farms to detect herd management practices which can be related to low $\mathrm{CH}_{4}$ emissions. Vanlierde et al. ${ }^{7}$ demonstrated the potential of using milk FT-MIR spectra to predict $\mathrm{CH}_{4}$ emissions from individual cows, and especially after inclusion of explanatory variables that take into account the stage of lactation for each cow. Vanlierde et al. ${ }^{8}$ developed a prediction model based on $\mathrm{CH}_{4}$ measurements from cows 
obtained using the $\mathrm{SF}_{6}$ tracer technique in Belgium and in Ireland. Vanlierde et al. ${ }^{9}$ also developed a prediction model based on $\mathrm{CH}_{4}$ measurements from cows in respiration chambers (RC) during diet comparison trials in France, Northern Ireland, Switzerland, Denmark and Germany. However, when these two prediction models were applied to 558,510 milk spectra from Holstein cows collected through the Walloon milk recording system between 1 January 2016 and 31 December 2017 (after removal of spectra with a Mahalanobis distance (GH) value higher than 5 to avoid extrapolation during the prediction step), the $\mathrm{CH}_{4}$ emission profiles during lactation were different (Figure 1). An increase in $\mathrm{CH}_{4}$ emissions is expected in the first weeks post-calving until a peak in milk yield, after which a decline in emissions until the end of the lactation occurs ${ }^{16}$. The model developed from $\mathrm{SF}_{6}$ observations does not predict the expected increase in emissions and instead predicts a relatively constant emission of $\mathrm{CH}_{4}$ at the beginning of lactation and then a decrease after 180 DIM. In contrast, the model based on RC observations predicts the increase in emissions in early lactation, but then the predictions increase again after 220 DIM, which is unexpected. Therefore, these two models need refinement.

Improved accuracy and robustness of these previously mentioned prediction models may be achieved by adding new reference data and/or by including additional explanatory variables. Both potential improvements will be investigated in the present study. Indeed, increasing the number of reference values in the calibration dataset and potential variability among animals (i.e. breeds, diet, milk yield, etc.) is a recognized way to improve the predictive model since it is known that development of a calibration equation requires a sufficiently varied set of data ${ }^{17}$. This is why the performance of a model to estimate $\mathrm{CH}_{4}$ emissions of dairy cows from milk FT-MIR spectra based on the combination of both available datasets ( $\mathrm{SF}_{6}$ and $\mathrm{RC}$ representing 1,116 records) was investigated. The incorporation of phenotypic information as explanatory variables in the prediction model may 
be beneficial. Shetty et al. ${ }^{18}$ included milk yield (MY), herd, parity (P), lactation stage and season as additional explanatory variables to predict $\mathrm{CH}_{4}$ emissions from milk MIR spectra. Their $\mathrm{CH}_{4}$ observations were obtained using the "sniffer" measurement approach, whereas the current study was based on $\mathrm{CH}_{4}$ measurements from $\mathrm{SF}_{6}$ and $\mathrm{RC}$ studies.

Within this context, this paper has two objectives: (1) to assess the effect of combining $\mathrm{SF}_{6}$ and $\mathrm{RC}$ reference $\mathrm{CH}_{4}$ data to construct a predictive model that explains more of the variability in $\mathrm{CH}_{4}$ emissions among cows using FT-MIR spectra and (2) to assess the effect of including additional phenotypic explanatory variables for cows such as MY, P and breed (B) to increase the accuracy of the model.

\section{MATERIALS AND METHODS}

\section{Existing datasets}

Two reference datasets were used to carry out the present study. These datasets were described by Vanlierde et al. ${ }^{8}$ for the data collected using the $\mathrm{SF}_{6}$ tracer gas technique $(\mathrm{n}=$ 532), and by Vanlierde et al. ${ }^{9}$ for data collected from RC studies $(\mathrm{n}=584)$. Each dataset consists of individual daily $\mathrm{CH}_{4}$ measurements from dairy cows with the corresponding milk FT-MIR spectra calculated as the average of the two milk spectra obtained from the morning and evening milkings weighted proportionally depending on the milk yield for each milking. This produces a daily FT-MIR spectra in a similar format to daily milk recording data and thus, ensures the practical application of the models. With the exception of spectra which predates the development of the standardization technique $(\mathrm{N}=557)$, milk FT-MIR spectra were standardized according to Grelet et al. ${ }^{19}$ to correct for the instrument interference and to ensure that the milk FT-MIR spectra are comparable regardless of the spectrometer used at the date of analysis. Also, a first derivative was applied to the milk FT-MIR spectra to correct the baseline drift as recommended by Soyeurt et al. ${ }^{20}$. The spectral regions studied were from wavenumbers 968 to $1,577 \mathrm{~cm}^{-1}, 1,720$ to $1,809 \mathrm{~cm}^{-1}$, and 2,561 to 2,966 $\mathrm{cm}^{-1}$ (i.e., 289 
spectral data points). As explained in detail by Vanlierde et al. ${ }^{7}$, constant (P0), linear (P1), and quadratic (P2) modified Legendre polynomials were computed from days in milk (DIM) on the day of $\mathrm{CH}_{4}$ measurement. The resulting Legendre polynomials were applied to each wavenumber of spectra to take into account the metabolic status of each cow during lactation. Each final modified spectrum was therefore based on a total of 867 data points (i.e. $3 \times 289$ data points).

\section{Cross-validation of $\mathrm{CH}_{4}$ values obtained using existing predictive models based on $\mathrm{SF}_{6}$ and $\mathrm{RC}$ observations}

To highlight the interest to merge the existing $\mathrm{SF}_{6}$ and $\mathrm{RC}$ reference datasets, the $\mathrm{CH}_{4}$ prediction models by Vanlierde et al. ${ }^{8}$ using $\mathrm{SF}_{6}$ measurements and by Vanlierde et al. ${ }^{9}$ using $\mathrm{RC}$ measurements were tested by cross-validation. The existing model based on $\mathrm{SF}_{6}$ observations ${ }^{8}$ was used to predict $\mathrm{CH}_{4}$ emissions from RC measurements, and the existing model based on $\mathrm{RC}$ observations ${ }^{9}$ was used to predict $\mathrm{CH}_{4}$ emissions from $\mathrm{SF}_{6}$ observations. To achieve this specific objective, some editing was applied on the datasets. At a spectral level, 106 observations from the RC-based dataset (18.4\% of the RC observations) had a GH $>3$, meaning that those spectra were too far from the values used in the calibration of the $\mathrm{SF}_{6}$ based prediction model. Consequently, to prevent spectral extrapolation, the $\mathrm{SF}_{6}$-based model was applied on only the remaining $478 \mathrm{RC}$ observations. Within the $\mathrm{SF}_{6}$-based dataset 27 observations (5.3\% of the $\mathrm{SF}_{6}$ observations) had a $\mathrm{GH}>3$. Thus, the RC-based prediction model was applied on the remaining 504 observations. The root mean square error of predictions (RMSEP) was calculated as well as the relative predictive error (RPE) defined as the ratio between each RMSEP and the mean of the corresponding observations.

\section{Combined $\mathrm{SF}_{6}$ and $\mathrm{RC}$ calibration dataset}

A new calibration dataset was developed from merging $\mathrm{SF}_{6}$ and RC-based datasets (n $=1,116$ ) to capture more variability among animals with the aim to create a more robust prediction model. The GH value was calculated for each spectrum based on their coordinates 
on principal components. Principal components were used since some of the spectral variables were highly correlated (11\% of spectral variables had an absolute Pearson correlation higher than 95\%). Spectra with a GH value greater than 3 were considered as different from the total reference dataset and removed ${ }^{21,22}$. Indeed, during the calibration process, the presence of outlying spectra in the reference dataset means we have gaps in the spectral data. This could negatively influence the quality of the prediction model. During this calibration process, 27 data values were considered outliers and discarded (2.4\% of the initial dataset). This is a little higher than reported by Withfield et al. ${ }^{23}$ who discarded $1 \%$ of the dataset based on a GH threshold $>3$. The final dataset for model development comprised $1,089 \mathrm{CH}_{4}$ records of $413 \pm 102 \mathrm{~g} / \mathrm{d}$ (mean $\pm \mathrm{SD} ; 513$ records from $\mathrm{SF}_{6}$ and 576 records from RC studies including 299 different cows between 7 and 322 DIM) and corresponding milk FT-MIR spectra (Table 1). Reference data were collected in seven countries: Belgium (BE) and Ireland (IE) for $\mathrm{SF}_{6}$ data, and United-Kingdom (UK), France (FR), Denmark (DK), Switzerland (CH) and Germany (D) for the RC data. Seven breeds were included in this dataset: Holstein (HO, 42 cows from BE, 98 from IE, 9 from CH, 5 from UK, 9 from FR, 9 from DK and 50 from D), Jersey (JER, 10 cows from DK), Brown Swiss (BS, 39 cows from $\mathrm{CH}$ ), Red Holstein (RH, 8 cows from $\mathrm{CH}$ ), Swedish Red Crossbred (SRX, 7 cows from UK), Norwegian Red (NR, 6 cows from IE) and Holstein Crossbred (HOX 6 cows from IE and 1 cow from $\mathrm{CH}$ ). Within the dataset $74 \%$ of cows were $\mathrm{HO}$ breed. A summary for each breed within the reference dataset is provided in Table 2. The DIM of each cow is included in the fitted model at the spectral level through the modified Legendre Polynomials. Table 3 gives details on the number of cow records within the reference dataset with regard to stage of lactation, the country of origin and the method used to measure enteric $\mathrm{CH}_{4}$ emissions. Of the 1,089 records, 291, 401 and 397 were from cows in their first, second or third and greater parity, respectively. The lack of data from cows in first lactation and measured in RC (Table 
1) is partly because heifers are not ideal for dietary trials as they have specific dietary needs due to growth requirements. Additionally, they are more difficult to manage in a RC.

Attention was paid to avoid increasing the error of the model that could be attributed to the merging of two datasets which used different methods to measure $\mathrm{CH}_{4}$ emissions. This step is detailed in Appendix 1, and found that, in this case, the $\mathrm{SF}_{6}$ and $\mathrm{RC}$ reference datasets can be combined without adjusting the $\mathrm{CH}_{4}$ values for either of the measurement methods used.

\section{Calibration process}

To avoid collinearity problems in the regression due to the high correlation existing between some spectral datapoints, a modified partial least square (PLS) regression was used for each calibration model as implemented in the WinISI software (version 4.6; Foss, Hillerød, Denmark) including an auto-scale process. This regression is based on PLS latent variables, which are a linear combination of explanatory variables built by taking into account the variability of $\mathrm{X}$ (i.e., matrix of explanatory variables) and y (i.e., vector of $\mathrm{CH}_{4}$ observations). More details about the PLS methodology can be found in Despagne et al. ${ }^{24}$. The number of latent variables was estimated using a 5-group internal cross-validation procedure. This means that the reference data set was divided randomly into five groups; five different calibration models were then developed on four groups by removing each time one of the groups. To assess the robustness of developed equations, $R^{2}$ of calibration $\left(\mathbf{R}^{2} \mathbf{c}\right)$ and of cross-validation $\left(\mathbf{R}^{2} \mathbf{c v}\right)$ as well as the standard errors of calibration (SEC) and crossvalidation (SECV) obtained in the PLS procedure of WinISI 4 software (Foss, Hillerod, Denmark) were compared. The data were not pre-corrected for the animal effect using a random model. Indeed, including this correction in the model would involve having a reference $\mathrm{CH}_{4}$ measurement for all cows for which we want to have a prediction. This last point would not be possible for all cows on the field for practical and financial issues. 


\section{Usefulness of including additional explanatory variables}

Previous studies by our group ${ }^{7,8,9}$ that described the performance of equations to estimate $\mathrm{CH}_{4}$ emissions were based only on milk FT-MIR spectra regressed by the modified Legendre polynomials to take into account the expected metabolic status of cows associated with their lactation stage. The inclusion of additional explanatory variables in the model could improve the accuracy of $\mathrm{CH}_{4}$ prediction. Explanatory variables based on information routinely recorded on commercial farms are preferable to ensure the applicability of the models developed to commercial farms. Therefore diet information was not added as an explanatory variable as dietary traits are not routinely collected in commercial farms. In the present study, milk yield, parity and breed information were included either individually or together as explanatory variables in model development, as well as the milk FT-MIR spectra, to predict $\mathrm{CH}_{4}$ emissions. This led to eight different calibration equations based on different combinations of explanatory variables. Abbreviations were given to these models in order to improve the clarity of the presentation of results (Table 4). Milk yield was considered as a quantitative variable in the model. Parity $(1,2$ and $>2)$ was also considered as a quantitative variable since a trend exists between $\mathrm{CH}_{4}$ emissions as the milk yield and the dry matter intake increase when the cow gets older ${ }^{25}$. Different breeds of cows were categorized as dummy variables: HO, JER, BS, RH, SRX and “others” for the remaining breeds (0: absence; 1: presence).

Similarly to the methodology detailed in Appendix $\mathbf{1}$ about the consideration of an adjustment based on the $\mathrm{CH}_{4}$ measurement method used, an analysis of variance was performed on residuals to test the significance of effects related to DIM (indirectly included in the spectral modification), parity, breed and country. Those variables were considered separately as fixed effects in a one-way ANOVA using Proc GLM procedure in SAS software (version 9.4., SAS Inst. Inc., Cary, NC, USA) for each of the eight models developed. 
In addition to the cross-validation procedure previously mentioned, a cow and country dependent external validation (CCDEV) was conducted using R version 3.5.2 (R Core Team, 2017, Vienna, Austria) and using packages “pls” version 2.7-126 and “cvTools” version 0.3.2 27 to evaluate the robustness of the models as done in a previous study ${ }^{9}$. As there are often several measurements on the same cow in the calibration dataset, this procedure prevents data from the same cow being present both in the calibration and in the validation set. All the data from $20 \%$ of the cows per country were removed simultaneously, resulting in the removal of all data from 8 cows from BE, 22 cows from IE, 10 cows from D, 12 from $\mathrm{CH}, 4$ from DK, 1 from FR and 2 from UK. The calibration model was developed on the remaining $80 \%$ of cows per country, and the model was subsequently tested on the removed data to avoid having the same animals in the calibration and in the validation set (unlike the aforementioned cross-validation procedure). The CCDEV process was repeated 500 times for each developed model to test a large number of combinations of randomly removed cows, and the variations of the $\mathrm{R}^{2}$ of CCDEV and of the RMSEP of CCDEV between each calibration model were used to compare them. This allowed evaluation of the models ability to estimate $\mathrm{CH}_{4}$ emissions for independent cows under the same conditions as cows included in the calibration data. In this study, these various conditions are dependent on the specific trials from each country.

Breed-specific models were tested to determine the accuracy of predictions within a specific breed. A PLS regression was performed as described before, with a 5-group cross validation process and a cow and breed dependent external validation (CBDEV). Regarding this CBDEV step, $20 \%$ of cows from one breed were removed randomly and simultaneously, with the calibration models developed on the remaining cows of this same breed, and subsequently tested using the removed data. The CBDEV process was repeated 200 times on each breed considered to test a maximum number of combinations of randomly selected cows. The $\mathrm{R}^{2}$ and the RMSEP for CBDEV were determined for each calibration model. 
In addition, the Akaike information criterion (AIC), the Bayesian information criterion (BIC) and the concordance correlation coefficient (CCC) were obtained to determine the optimal prediction model (i.e. lowest values for AIC and BIC and the highest value for CCC).

\section{RESULTS AND DISCUSSION}

\section{External validation of existing predictive models based on $\mathrm{SF}_{6}$ and $\mathrm{RC}$ observations}

The calibration model based on $\mathrm{SF}_{6}$ observations assessed using $478 \mathrm{RC}$ observations leading to a RMSEP of $105 \mathrm{~g}$ of $\mathrm{CH}_{4} /$ day (RPE of 26.2\%). The RMSEP for the model based on RC observation assessed using $504 \mathrm{SF}_{6}$ observations was $140 \mathrm{~g}$ of $\mathrm{CH}_{4} / \mathrm{day}$ (RPE of 32.6\%). These resulting RMSEPs values were expected due to differences between both datasets in terms of technological (reference methods used to measure $\mathrm{CH}_{4}$ ), zootechnical (breeds, management, genetics, study conditions, etc.) and phenotypic (range in $\mathrm{CH}_{4}$ values, milk yields, etc.) attributes. Figure 2 shows predicted $\mathrm{CH}_{4}$ emissions using either the $\mathrm{SF}_{6}$ - and RC-based models against observed $\mathrm{CH}_{4}$ emissions for the cross-validation test. The aforementioned lower RMSEP value using the model based on $\mathrm{SF}_{6}$ observations on the RC data can be related to the tighter distribution of the validation dataset in Figure 2 a) than in Figure $2 \mathrm{~b}$ ). The better predictive performance of the equation based on $\mathrm{SF}_{6}$ observations was also expected due to the greater range of reference $\mathrm{CH}_{4}$ values included in the $\mathrm{SF}_{6}$ reference dataset in comparison with the RC-based reference dataset.

The equation based on $\mathrm{SF}_{6}$ observations applied to RC data, specifying the country of origin, resulted in RMSEP values of $152 \mathrm{~g} \mathrm{CH}_{4} / \mathrm{d}$ for $\mathrm{UK}$, $79 \mathrm{~g} \mathrm{CH}_{4} / \mathrm{d}$ for $\mathrm{FR}, 121 \mathrm{~g} \mathrm{CH}_{4} / \mathrm{d}$ for DK, $65 \mathrm{~g} \mathrm{CH}_{4} / \mathrm{d}$ for $\mathrm{CH}$ and $87 \mathrm{~g} \mathrm{CH}_{4} / \mathrm{d}$ for D. The $\mathrm{CH}$-dataset had the lowest RMSEP. It is interesting to note that if only data from two of the three experiments included in the $\mathrm{CH}$ dataset were considered (111 reference data from 46 cows), the $\mathrm{CH}$-statistics were significantly improved with a RMSEP of $60 \mathrm{~g} \mathrm{CH}_{4} / \mathrm{d}$. Differences can be observed within and 
between countries depending on the dataset in terms of the accuracy of predictions. This should be linked with the differences in data from each country regarding observed values and zootechnical attributes (Tables 1, 2 and 3).

More than the zootechnical characteristics of the animals, Figure 3 graphically represents the milk FT-MIR spectrum as a function of the reference dataset ( $\mathrm{SF}_{6}$ vs. RC) and for the first three principal components (explaining $82 \%$ of the total spectral variability). It can be noted that the information and the variability they contain respectively are complementary. This also infers that the models were not robust enough to perform external validation tests from one country or one reference method to another in the current state. Therefore, there is a real interest to combine these $\mathrm{CH}_{4}$ reference data to develop a new model.

This section highlights the importance of ensuring that the characteristics of animals or their milk FT-MIR spectra for which predictions are required are represented in the calibration dataset used to develop the model.

\section{Calibration equations combining $R C$ and $S_{6} F_{6}$ reference datasets and inclusion of phenotypic information as explanatory variables}

Calibration and cross-validation statistical results for the eight developed calibration equations built from raw $\mathrm{CH}_{4}$ data and including different combinations of milk yield, parity and breed in addition to milk spectra as explanatory variables are detailed in Table 5 . With the addition of zootechnical information as explanatory variables, $\mathrm{R}^{2} \mathrm{C}$ and $\mathrm{R}^{2} \mathrm{Cv}$ slightly increased compared to the MS model. Consequently, a decrease in SEC and SECV was expected with the inclusion of additional phenotypic information (i.e. milk yield, parity and breed). The highest $\mathrm{R}^{2}$ values and minimum errors were observed for the MSMYPB model with an $\mathrm{R}^{2} \mathrm{C}$ of 0.73 , a R ${ }^{2} \mathrm{CV}$ of 0.68 , a SEC of $53 \mathrm{~g} \mathrm{CH}_{4} / \mathrm{d}$ and a SECV of $57 \mathrm{~g} \mathrm{CH}_{4} / \mathrm{d}$. Regarding the CCDEV procedure, MSMYPB presented the highest $\mathrm{R}^{2}(0.60)$ and lowest 
RMSEP (65 $\mathrm{g} \mathrm{CH}_{4} / \mathrm{d}$ ). Moreover, the MSMYPB model presented the highest CCC value (0.81 meaning accurate predictive ability $\left.{ }^{28}\right)$ and the lowest AIC and BIC values (-186 and 181 respectively from the AIC and BIC of the MS model).

In comparison with the statistics obtained with the models based on one kind of measurement method, $\mathrm{R}^{2} \mathrm{C}$ and $\mathrm{R}^{2} \mathrm{Cv}$ shown in Table 5 (between 0.68 and 0.73 , and between 0.64 and 0.68 respectively) are lower than for the equation based only on $\mathrm{SF}_{6}$ observations ${ }^{8}$ ( 0.74 and 0.70 , respectively) and higher than for the equation based only on RC observations ${ }^{9}$ (0.65 and 0.57, respectively). Regarding the errors, the SEC and SECV obtained with the models developed here and shown in Table 5 (between 58 and 53, and between 61 and 57 $\mathrm{CH}_{4} / \mathrm{d}$, respectively) are all lower than the ones obtained for the existing model based on $\mathrm{SF}_{6}$ observations $^{8}$ (66 and $70 \mathrm{~g} \mathrm{CH}_{4} / \mathrm{d}$, respectively) and greater than the ones obtained for the existing model based on RC observations ${ }^{9}$ (43 and $47 \mathrm{~g} \mathrm{CH}_{4} / \mathrm{d}$, respectively). The statistical results for the MSMYPB version were similar to the $\mathrm{R}^{2} \mathrm{C}$ and $\mathrm{R}^{2} \mathrm{Cv}$ for the model based on $\mathrm{SF}_{6}$ observations $^{8}$ with lower errors, which suggests an improvement of accuracy. Moreover, by considering a higher number of observations the MSMYPB model described more of the variability in $\mathrm{CH}_{4}$ emissions than previous models ${ }^{8,9}$ based on $\mathrm{SF}_{6}$ and $\mathrm{RC}$ observations, leading to an improvement of the robustness of the model. Figure 4 illustrates the $\mathrm{CH}_{4}$ observations compared to the predictions obtained with the MSMYPB model.

Based on the reference datasets available for this study, RPEcv and CCC parameters reach respectively $14.1 \%$ and 0.81 for the MSMYPB model (Table 5). These statistics are slightly better than the best models based on ingestion, dietary components and/or animal attributes (but no milk MIR spectra) summarized in Niu et al. ${ }^{29}$ (respectively $14.7 \%$ and 0.76 in the best conditions). The advantage of predictive models based on milk MIR spectra is that spectra are routinely collected and permit to have easily a value at individual animal level at large scale. MSMYPB model developed in this study also has better statistics than Shetty et 
al. ${ }^{18}$ who observed a $\mathrm{R}^{2}$ of prediction and a RMSEP of 0.13 and $111 \mathrm{~L}$ of $\mathrm{CH}_{4} / \mathrm{d}$ respectively for the model based only on the milk FT-MIR spectra while these parameters were about 0.39 and 94 L/d respectively when they also considered MY, herd, P, DIM and season as variables in the model.

Figure 5 details the trends of the predictions obtained when these new models are applied on the same spectral dataset described in the introduction ( $\mathrm{n}=558,510$ milk FT-MIR spectra from Holstein cows collected through the Walloon milk recording system) as a function of the DIM of the animal. The $\mathrm{CH}_{4}$ curves of the eight models are very similar and are now much more in accordance with the literature ${ }^{16}$, with an increase during the first weeks of lactation followed by a moderate decrease until the end of lactation.

The effect on the residuals of adding DIM, parity, country and breed into each of the eight developed models are specified in Table 6. It can be noted that DIM had no significant effect on the residuals. Since the lactation stage is accounted for by using the modified Legendre polynomials to regress spectral data, this non-significant influence of DIM on the residuals was expected. The daily milk yield has a significant impact on the residuals for the models where milk yield is not an explanatory value of the regression. So, considering milk yield in the model is relevant. The inclusion of parity in the regression model has a low influence compared to other variables (Table 5). When parity is not included in the model, the resulting residuals are significantly dependent on the parity of the cow (Table 6). Adding parity information in the model seems therefore to be appropriate. The country factor has a highly significant effect on residuals in models where breed was excluded. This is because some breeds are represented in only one country (e.g. JER, BS, NR). Finally, breed had a significant effect on the residuals in all models including those with breed as a factor. Some breeds had a very low representation in the calibration set and were also linked with particular experimental protocols and diet, which can explain this effect. However, the breed effect was 
less significant when breed was included in the model as a parameter in combination with parity or/and milk yield (Table 6). Accordingly, these phenotypic combinations permitted a better description of the animal and its performance than breed alone. Models with MSPB and MSMYPB were found to best describe variability in $\mathrm{CH}_{4}$ among this dataset.

Even for MSPB and MSMYPB models, the breed effect was not totally accounted for by the model as the effect on the residual was still significant. Therefore, the prediction accuracy of cross-validation can be impacted as the CCDEV procedure was conducted randomly regarding cows selected for calibration or validation datasets.

The results obtained during the CBDEV procedure are given in Table 7. Depending on the version of the equation, the average $\mathrm{R}^{2}$ values ranged from 0.57 to 0.60 for the $\mathrm{HO}$ breed. At the statistical level, the MSMYP model presents the most interesting combination of highest coefficients of determination and lowest errors for both calibration and validations steps.

The statistical performance of the CBDEV models were not greater than the predictive models based on the total dataset with all breeds included and were similar to the results obtained during the CCDEV procedure. Data from other breeds may bring added value to the models. This would allow predictions from milk spectra collected on additional breeds than $\mathrm{HO}$ as long as there is not sufficient data to consider the development of breed-specific models.

The combined information given by including milk yield, parity and breed improved the prediction of daily $\mathrm{CH}_{4}$ emissions of dairy cows by milk FT-MIR spectra. As the phenotypic information included is routinely available, the MSMYPB model can be applied to commercial farms. The prediction model can be chosen depending on available phenotypic information. The more explanatory variables included that describe the animal, the better the 
accuracy of the prediction model. Therefore, inclusion of other routinely available traits presents the possibility of further improvement. There is still potential for this model to be improved and to evolve by the inclusion of new explanatory variables and as new data becomes available.

A next step will be to determine the performance of the models developed in the present study under practical conditions by measuring the methane emissions of animals estimated to differ in this trait. Once the equations prove to be robust in this respect, the use of milk FT-MIR spectra could be introduced as a tool for estimating $\mathrm{CH}_{4}$ emissions for a large number of dairy cows. In addition, the present observations confirm the necessity to collaborate between research teams from different countries to test the models in specific local conditions and to include local variability (at spectral and phenotypical levels) in the reference dataset if it is not yet present. This is why a further improvement of the robustness of the models could occurs in the future with the availability of such new relevant reference databases.

\section{CONCLUSIONS}

The models developed in the current study combining $\mathrm{CH}_{4}$ observations obtained with $\mathrm{SF}_{6}$-tracer and $\mathrm{RC}$ measurement methods accounted for more variability in spectral and zootechnical data. They explained more variation in $\mathrm{CH}_{4}$ emissions among cows and consequently are more robust than previous versions based on those datasets considered independently. Additionally, the inclusion of milk yield, parity and breed as explanatory variables in the prediction model improved the description of variability. Moreover, the trends of the predictions obtained by these new models applied on a large spectral database adjusted for the lactation stage of animals are now more in accordance with the literature. By taking 
care of removing outlying spectral data and cow phenotypic information not included in the model, an improvement in FT-MIR derived $\mathrm{CH}_{4}$ predictions under practical conditions is expected.

\section{ACKNOWLEDGEMENTS}

The authors are grateful to their fellow researchers with regard to collecting methane and milk samples. Part of the work and facilitation of data exchanges have been feasible through projects funded by European Union’s Seventh Framework Programme: GreenHouseMilk (https://cordis.europa.eu/project/rcn/92792/) which particularly permitted exchange of data with Teagasc Moorepark in Ireland (grant agreement $n^{\circ} 238562$ ); and GplusE (https://cordis.europa.eu/project/rcn/111473/), especially for research conducted at the Agri-Food and Biosciences Institute (AFBI) in Northern Ireland (grant agreement $n^{\circ} 613689$ ). The views expressed in this publication are the sole responsibility of the authors and do not necessarily reflect the views of the European Commission. The OptiMIR (INTERREG IVB North-West Europe funded; https://www.keep.eu/project/7026/) and the COST Methagene (COST-Horizon 2020 funded; https://www.cost.eu/actions/FA1302/) European projects are gratefully acknowledged for facilitating networking between research teams and data exchange. The authors thank the Walloon Breeding Association (Ciney, Belgium) and Comité du lait (Battice, Belgium) for providing access to data related to the Walloon milk recording. Qualitas AG is sincerely thanked for initiating exchanges with Switzerland on this topic. The Association of Swiss Cattle Breeders (Zollikofen, Switzerland) is acknowledged for providing the milk Fourier transform mid-infrared spectral data of the Swiss samples. Research conducted at Leibniz Institute for Farm Animal Biology (FBN) in Germany was partially funded by the optiKuh project supported by the German Federal Ministry of Food and Agriculture (BMBL) through the Federal Office for Agriculture and Food (BLE). Research conducted in France at the French National Institute for Agricultural Research (INRA) was 
funded by the French National Research Agency (ANR) through the Joint Programming Initiative on Agriculture, Food Security and Climate Change (FACCE-JPI) Global Network program (ANR-13-JFAC-0003-01). Research conducted in Denmark at Aarhus University was funded by the Danish Milk Levy Fund and Aarhus University.

\section{REFERENCES}

1. Core Writing Team, Pachauri RK, Meyer LA (eds). Climate Change 2014: Synthesis Report. Contribution of Working Groups I, II and III to the Fifth Assessment Report of the Intergovernmental Panel on Climate Change. Geneva: IPCC; 2014.

2. Gerber PJ, Steinfeld H, Henderson B, Mottet A, Opio C, Dijkman J, Falcucci A, Tempio G. (eds). Tackling Climate Change through Livestock: A Global Assessment of Emissions and Mitigation Opportunities. Rome: Food and Agriculture Organization of the United Nations (FAO); 2013.

3. Negussie E, de Haas Y, Dehareng F, Dewhurst RJ, Dijkstra J, Gengler N, Morgavi DP, Soyeurt H, van Gastelen S, Yan T and Biscarini F, Invited review: Large-scale indirect measurements for enteric methane emissions in dairy cattle: A review of proxies and their potential for use in management and breeding decisions. J Dairy Sci 100(4):2433-2453 (2017). https://doi.org/10.3168/jds.2016-12030

4. Chilliard Y, Martin C, Rouel J and Doreau M, Milk fatty acids in dairy cows fed whole crude linseed, extruded linseed, or linseed oil, and their relationship with methane output. J Dairy Sci 92:5199-5211 (2009). https://doi.org/10.3168/jds.2009-2375

5. van Gastelen S and Dijkstra J, Prediction of methane emission from lactating dairy cows using milk fatty acids and mid-infrared spectroscopy. J Sci Food Agric 96(12):3963-3968 (2016). https://doi.org/10.1002/jsfa.7718

6. Van Lingen HJ, Crompton LA, Hendriks WH, Reynolds CK and Dijkstra J, Metaanalysis of relationships between enteric methane yield and milk fatty acid profile in dairy cattle. J Dairy Sci 97(11):7115-7132 (2014). https://doi.org/10.3168/jds.2014$\underline{8268}$

7. Vanlierde A, Vanrobays M-L, Dehareng F, Froidmont E, Soyeurt H, McParland S, Lewis E, Deighton MH, Grandl F, Kreuzer M, Gredler B, Dardenne P, Gengler N, Hot Topic: Innovative lactation stage dependent prediction of methane emissions from milk mid-infrared spectra. J Dairy Sci 98(8):5740-5747 (2015). https://doi.org/10.3168/jds.2014-8436

8. Vanlierde A, Vanrobays M-L, Gengler N, Dardenne P. Froidmont E, Soyeurt H, McParland S, Lewis E, Deighton MH, Mathot M and Dehareng F, Milk mid-infrared 
spectra enable prediction of lactation-stage-dependent methane emissions of dairy cattle within routine population-scale milk recording schemes. Anim Prod Sci 56:258264 (2016). https://doi.org/10.1071/AN15590

9. Vanlierde A, Soyeurt H, Gengler N, Colinet FG, Froidmont E, Kreuzer M, Grandl F, Bell M, Lund P, Olijhoek DW, Eugène M, Martin C, Kuhla B and Dehareng F, Short communication: Development of an equation for estimating methane emissions of dairy cows from milk Fourier transform mid-infrared spectra by using reference data obtained exclusively from respiration chambers. J Dairy Sci 101(8):7618-7624 (2018). https://doi.org/10.3168/jds.2018-14472

10. Dehareng F, Delfosse C, Froidmont E, Soyeurt H, Martin C, Gengler N, Vanlierde A and Dardenne P, Potential use of milk mid-infrared spectra to predict individual methane emission of dairy cows. Animal 6(10):1694-1701 (2012). https://doi.org/10.1017/S1751731112000456

11. van Gastelen S, Mollenhorst H, Antunes-Fernandes EC, Hettinga KA, van Burgsteden GG, Dijkstra J and Rademaker JLW, Predicting enteric methane emission of dairy cows with milk Fourier-transform infrared spectra and gas chromatography-based milk fatty acid profiles. J Dairy Sci 101(6):5582-5598 (2018). https://doi.org/10.3168/jds.2017-13052

12. Bittante G and Cipolat-Gotet C, Direct and indirect predictions of enteric methane daily production, yield, and intensity per unit of milk and cheese, from fatty acids and milk Fourier-transform infrared spectra. J Dairy Sci 101(8):7219-7235 (2018). https://doi.org/10.3168/jds.2017-14289

13. de Haas Y, Pszczola M, Soyeurt H, Wall E, and Lassen J, Invited review: Phenotypes to genetically reduce greenhouse gas emissions in dairying. J Dairy Sci 100(2):855870 (2017). https://doi.org/10.3168/jds.2016-11246

14. Kandel PB, Vanrobays ML, Vanlierde A, Dehareng F, Froidmont E, Gengler N and Soyeurt $\mathrm{H}$, Genetic parameters of mid-infrared methane predictions and their relationships with milk production traits in Holstein cattle. J Dairy Sci 100(7):55785591 (2017). https://doi.org/10.3168/jds.2016-11954

15. Vanrobays M-L, Bastin C, Vandenplas J, Hammami H, Soyeurt H, Vanlierde A, Dehareng F, Froidmont E and Gengler N, Changes throughout lactation in phenotypic and genetic correlations between methane emissions and milk fatty acid contents predicted from milk mid-infrared spectra. J Dairy Sci 99(9):7247-7260 (2016). https://doi.org/10.3168/jds.2015-10646

16. Garnsworthy PC, Craigon J, Hernandez-Medrano JH, Saunders N, Variation among individual dairy cows in methane measurements made on farm during milking. $J$ Dairy Sci 95:3181-3189 (2012). http://dx.doi.org/10.3168/jds.2011-4606 
17. Davies AMC and Fearn T. Back to basics: calibration statistics. Spectroscopy Europe 18:31-32 (2006).

18. Shetty N, Difford G, Lassen J, Løvendahl P and Buitenhuis AJ, Predicting methane emissions of lactating Danish Holstein cows using Fourier transform mid-infrared spectroscopy of milk. J Dairy Sci 100: 9052-9060 (2017). http://dx.doi.org/10.3168/jds.2017-13014

19. Grelet C, Fernandez Pierna JA, Dardenne P, Soyeurt H, Vanlierde A, Colinet F, Bastin C, Gengler N, Baeten V and Dehareng F, Standardization of milk mid-infrared spectrometers for the transfer and use of multiple models. J Dairy Sci 100:7910-7921 (2017). https://doi.org/10.3168/jds.2017-12720

20. Soyeurt H, Dehareng F, Gengler N, McParland S, Wall EPBD, Berry DP, Coffey M and Dardenne P, Mid-infrared prediction of bovine milk fatty acids across multiple breeds, production systems, and countries. J Dairy Sci 94(4):1657-1667 (2011). https://doi.org/10.3168/jds.2010-3408

21. Shenk JS and Westerhaus MO, Population definition, sample selection, and calibration procedures for near infrared reflectance spectroscopy. Crop Sci 31(2):469-474 (1990). doi:10.2135/cropsci1991.0011183X003100020049x

22. Soyeurt H, Bastin C, Colinet FG, Arnould VM-R, Berry DP, Wall E,Dehareng F, Nguyen HN, Dardenne P, Schefers J,Vandenplas J,WeigelK,Coffey M, Théron L, Detilleux J, Reding E, Gengler N, McParland S, Mid infrared prediction of lactoferrin content in bovine milk: potential indicator of mastitis. Animal 6:1830-1838 (2012). https://doi.org/10.1017/S1751731112000791

23. Whitfield RG, Gerger ME and Sharp RL, Near-infrared spectrum qualification via mahalanobis distance determination. Appl Spectrosc 41(7):1204-1213 (1987).

24. Despagne F, Massart DL and Chabot P, Development of a robust calibration model for nonlinear in-line process data. Analytical chemistry 72(7):1657-1665 (2000).

25. Bittante G, Cecchinato A and Schiavon S, Dairy system, parity, and lactation stage affect enteric methane production, yield, and intensity per kilogram of milk and cheese predicted from gas chromatography fatty acids. Journal of dairy science, 101(2):17521766 (2018). https://doi.org/10.3168/jds.2017-13472

26. Mevik BH, Wehrens R and Hovde Liland K, (2019). pls: Partial Least Squares and Pri ncipal Component Regression. R package version 2.7-1. https://CRAN.R-project.org/p $\underline{\text { ackage }=p l s}$

27. Alfons A, (2012). cvTools: Cross-validation tools for regression models. R package ve rsion 0.3.2. https://CRAN.R-project.org/package $=$ cvTools 
28. Altman DG, (1997). Practical statistics for medical research. Chapman Hall, London, UK.

29. Niu M, Kebreab E, Hristov AN, Oh J, Arndt C, Bannink A, Bayat AR, Brito AF, Boland T, Casper D, Crompton LA, Dijkstra J, Eugène MA, Garnsworthy PC, Haque MN, Hellwing ALF, Huhtanen P, Kreuzer M, Kuhla B, Lund P, Madsen J, Martin C, McClelland SC, McGee M, Moate PJ, Muetzel S, Muñoz C, O'Kiely P, Peiren N, Reynolds CK, Schwarm A, Shingfield KJ, Storlien TM, Weisbjerg MR, Yáñez-Ruiz $\mathrm{DR}$ and $\mathrm{Yu} \mathrm{Z}$, Prediction of enteric methane production, yield and intensity in dairy cattle using an intercontinental database. Global Change Biology 24(8), pp. 3369-3389 (2018). https://doi.org/10.1111/gcb.14094 


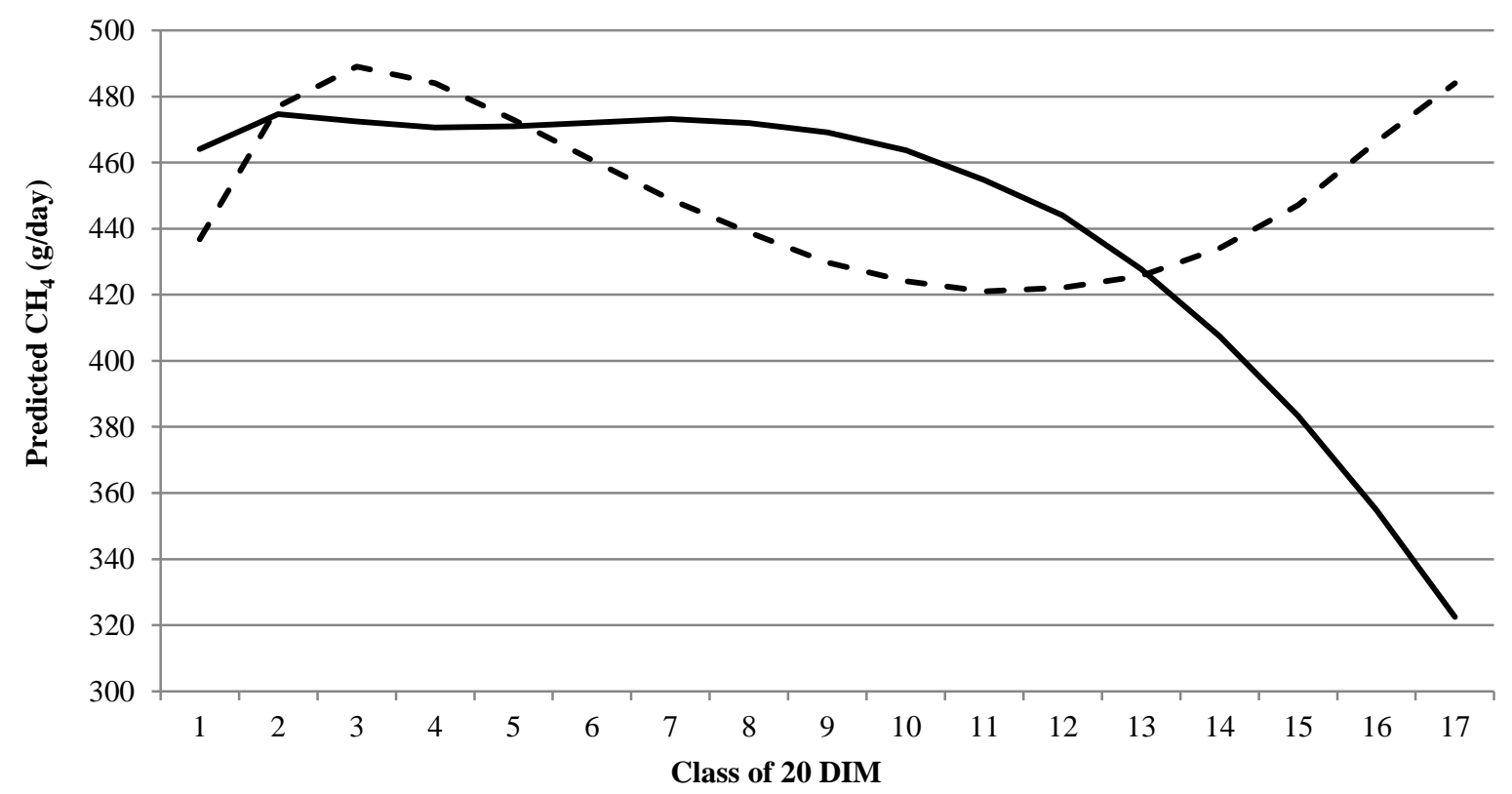

Figure 1: Average predicted $\mathrm{CH}_{4}$ (g/day) for each class of 20 days in milk (DIM) during lactation using equation of Vanlierde et al. ${ }^{8}\left(-\mathrm{SF}_{6}\right)$ or equation of Vanlierde et al. ${ }^{9}(---$ Respiration chamber) based on spectral data collected from Holstein cows through the Walloon milk recording system between 1 January 2016 and 31 December 2017 ( $\mathrm{n}=$ $538,510)$.

a)

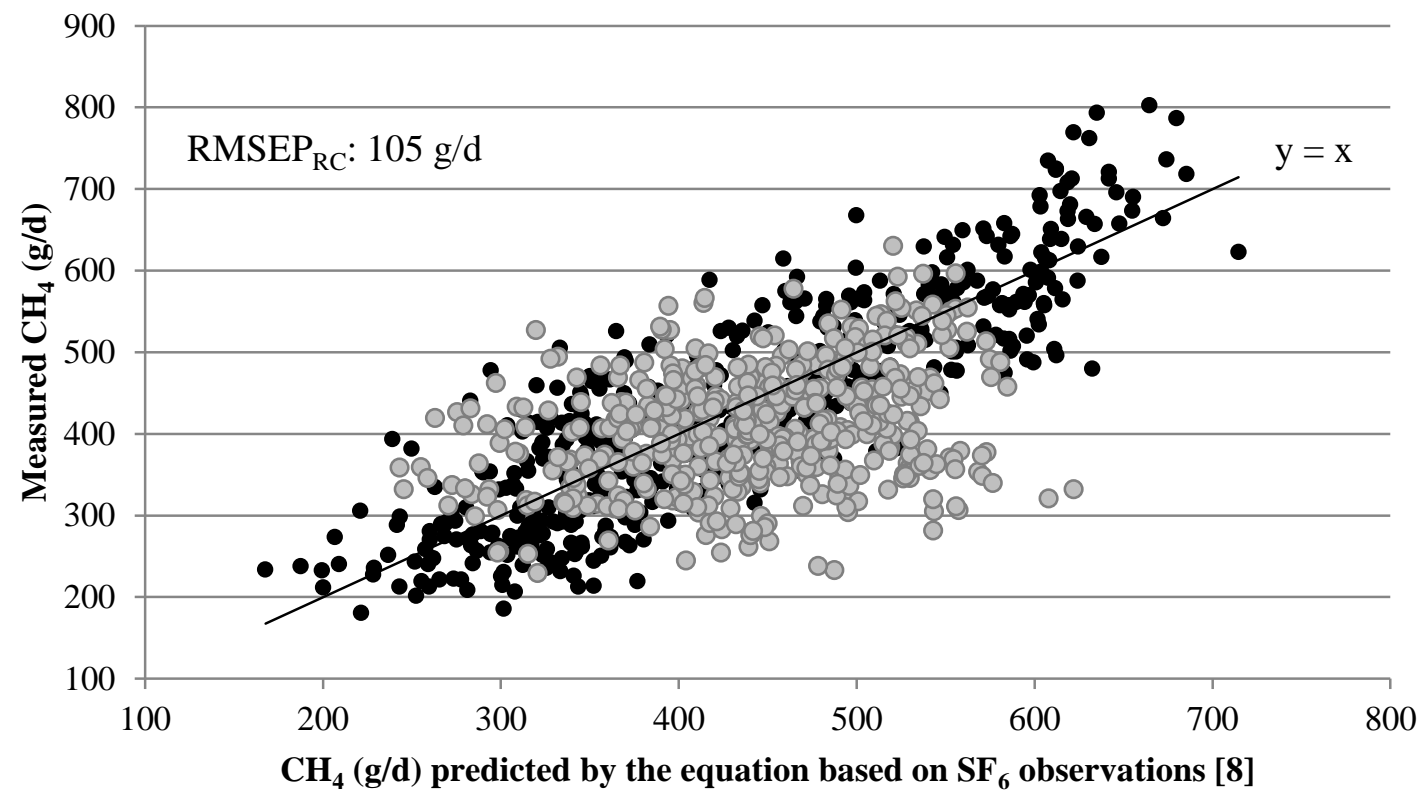

b) 


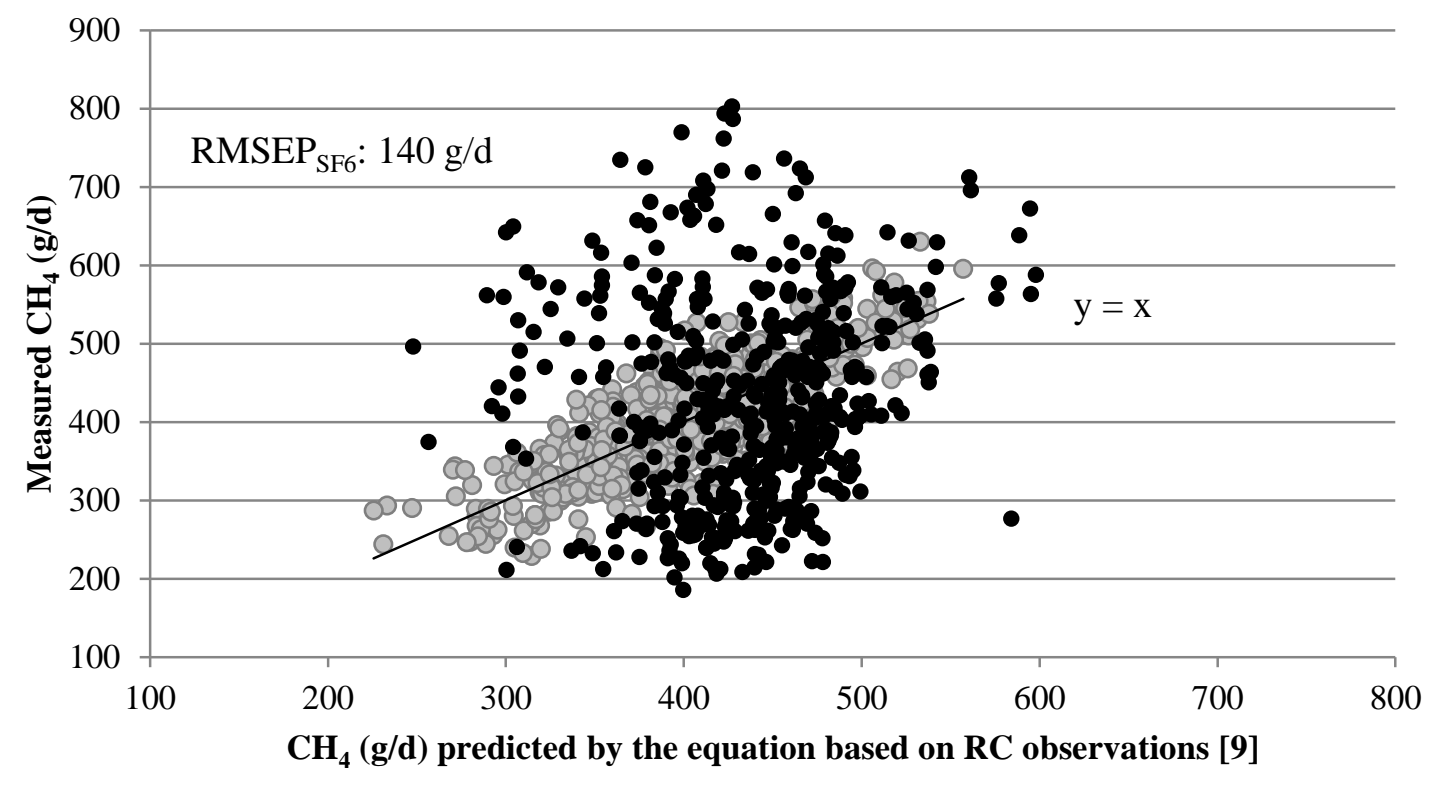

Figure 2: Measured methane emissions ( $\mathrm{g} \mathrm{CH}_{4}$ per day) using $\mathrm{SF}_{6}$ tracer technique $(\bullet)$ or respiration chamber $(\bullet)$ methods against predicted methane (a) using equation calibrated only on data collected with $\mathrm{SF}_{6}$ tracer technique ${ }^{8}$ (validation set is the $\mathrm{RC}$ dataset) or (b) using equation calibrated only on data collected with respiration chamber technique ${ }^{9}$ (validation set is the $\mathrm{SF}_{6}$ dataset). 


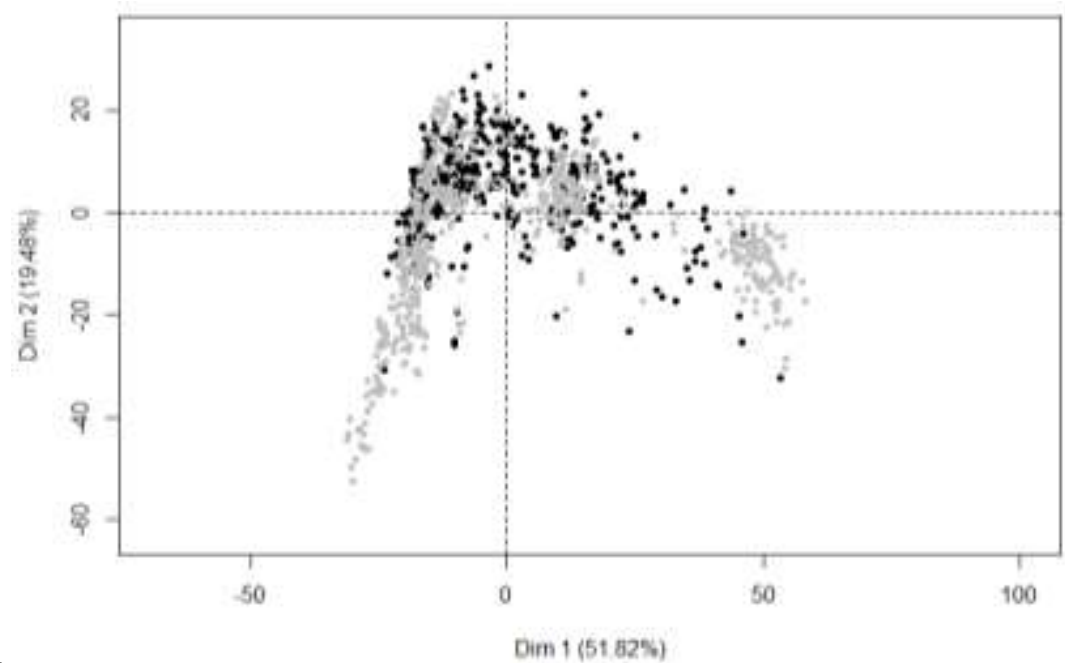

a)

b)
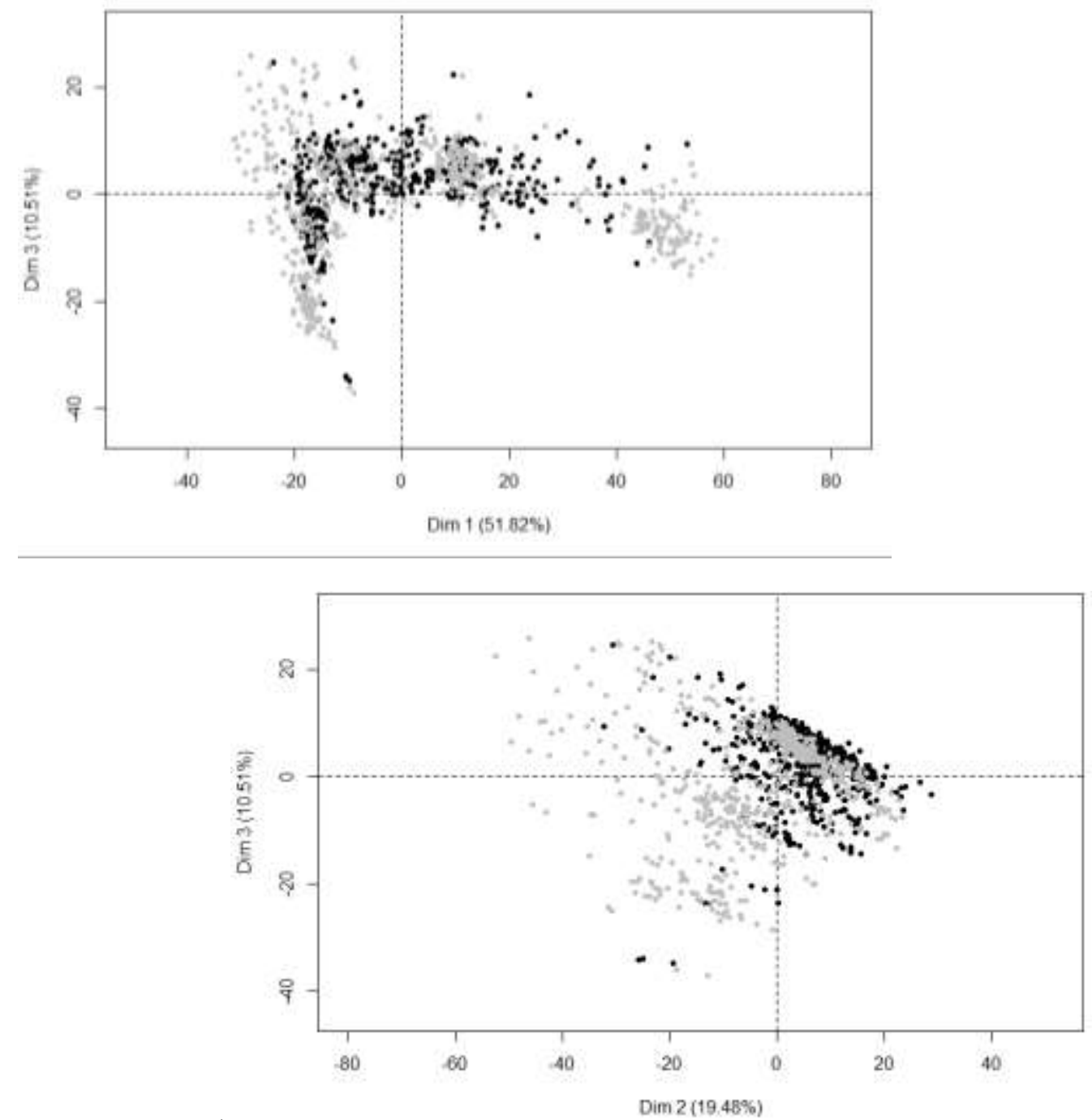

c)

Figure 3: Graphical representation of reference milk FT-MIR spectra as a function of the first three principal components $(\mathrm{PC})$ and the original dataset $\left(\bullet=\mathrm{SF}_{6}\right.$ dataset; $\bullet=\mathrm{RC}$ dataset $) ;$ a) $\mathrm{PC} 2$ vs. PC 1, b) PC 3 vs. PC 1, c) PC 3 vs. PC 2 


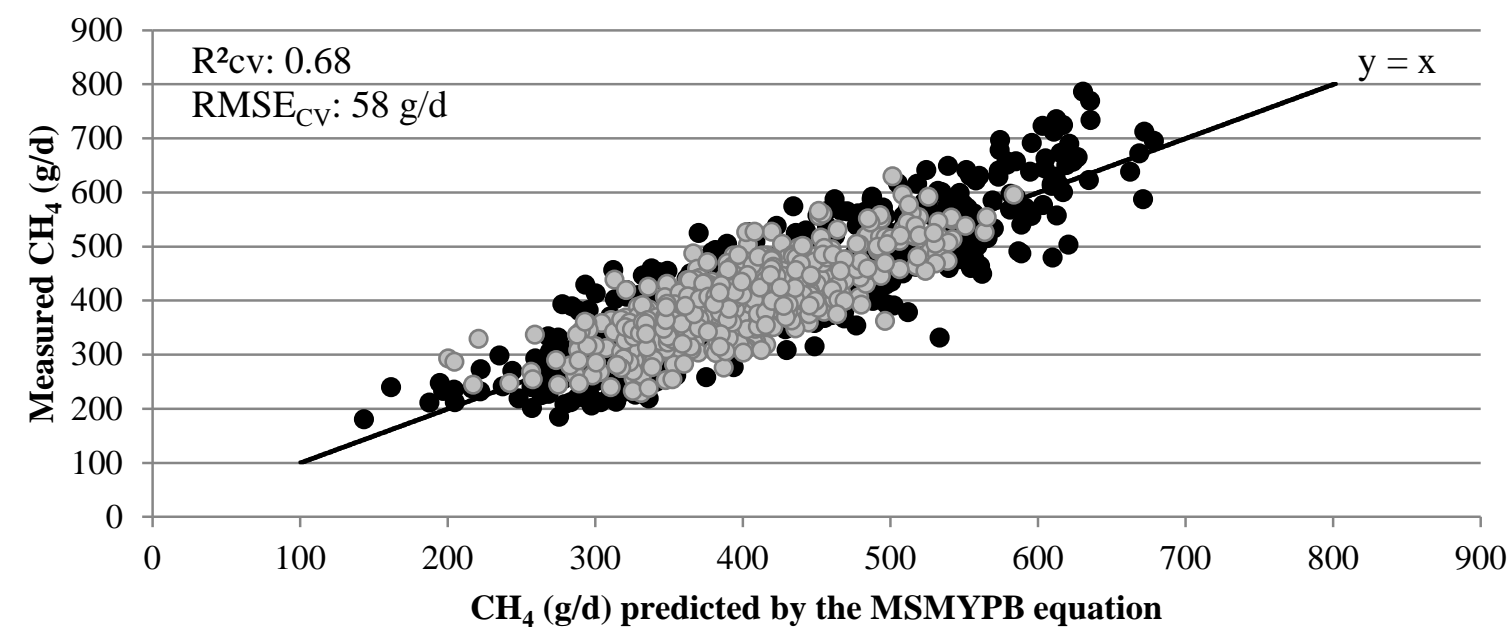

Figure 4: Measured methane ( $\mathrm{g} \mathrm{CH}_{4}$ per day) from $\mathrm{SF}_{6}$ and respiration chamber datasets $(\bullet$ : data collected with the $\mathrm{SF}_{6}$ tracer technique ${ }^{8}, \mathrm{n}=531 ; \bullet$ : data collected with the respiration chamber method $^{9}, \mathrm{n}=576$ ) compared to predicted values using the MSMYPB model.

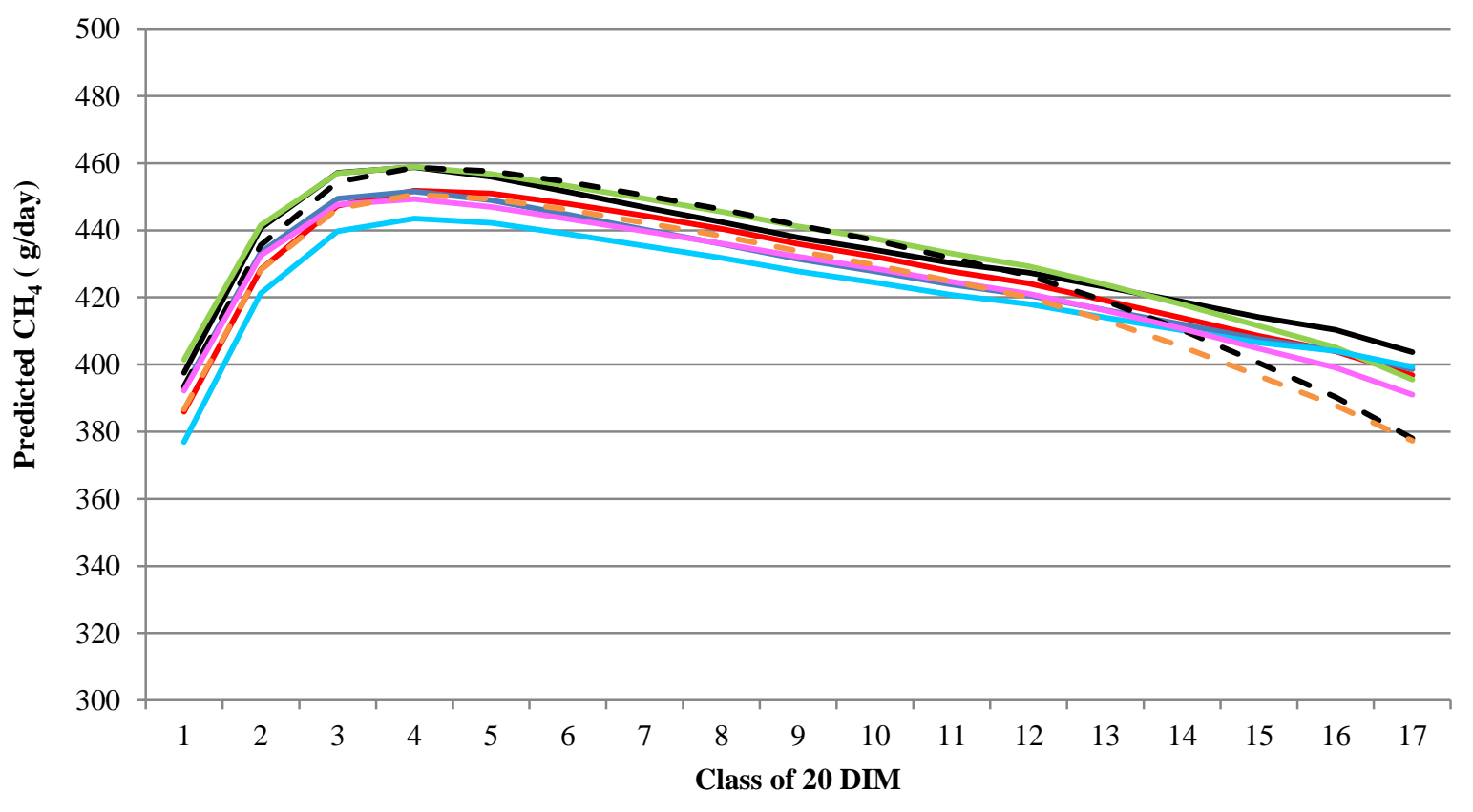

Figure 5: Average $\mathrm{CH}_{4}$ predictions (g/day) from spectral data collected from Holstein cows through the Walloon milk recording system between 1 January 2016 and 31 December 2017 $(\mathrm{n}=538,510)$ adjusted for days in milk (DIM) and explanatory variables included in the prediction model (— MS; — MSMY, — MSP, — MSB, — MSMYP, - - MSMYB, MSPB, - - MSMYPB). 
Table 1: The number and the range of methane $\left(\mathrm{CH}_{4}\right)$ records, number of cows and in each parity for data obtained from $\mathrm{SF}_{6}$ and respiration chamber $(\mathrm{RC})$ studies across countries included in the present study.

\begin{tabular}{|c|c|c|c|c|c|c|c|c|}
\hline \multirow{2}{*}{$\begin{array}{l}\text { Reference } \\
\text { method }\end{array}$} & \multirow{2}{*}{ Country } & \multirow{2}{*}{$\mathrm{n}$ data } & \multirow{2}{*}{$\mathrm{n}$ cows } & \multicolumn{3}{|c|}{ Parity (n cows) } & \multirow{2}{*}{\multicolumn{2}{|c|}{$\begin{array}{c}\mathrm{CH}_{4}(\mathrm{~g} / \mathrm{d}) \\
\text { mean } \pm \mathrm{SD}\end{array}$}} \\
\hline & & & & 1 & 2 & $>2$ & & \\
\hline \multirow{2}{*}{$\mathrm{SF}_{6}$} & $\mathrm{BE}$ & 252 & 42 & 16 & 11 & 15 & $510 \pm 105$ & \multirow{2}{*}{$427 \pm 127$} \\
\hline & IE & 261 & 110 & 45 & 29 & 36 & $347 \pm 89$ & \\
\hline \multirow{6}{*}{$\mathrm{RC}$} & UK & 24 & 12 & I & 3 & 9 & $365 \pm 44$ & \multirow{5}{*}{$400 \pm 72$} \\
\hline & FR & 81 & 9 & I & 7 & 2 & $366 \pm 61$ & \\
\hline & DK & 129 & 19 & 8 & 4 & 7 & $367 \pm 64$ & \\
\hline & $\mathrm{CH}$ & 135 & 57 & 8 & 16 & 33 & $451 \pm 75$ & \\
\hline & $\mathrm{D}$ & 207 & 50 & I & 34 & 16 & $405 \pm 60$ & \\
\hline & TOTAL & 1,089 & 299 & 77 & 104 & 118 & \multicolumn{2}{|c|}{$413 \pm 102$} \\
\hline
\end{tabular}

SD: standard deviation; Belgium (BE), Ireland (IE), United-Kingdom (UK), France (FR), Denmark (DK), Switzerland (CH) and Germany (D)

Table 2: Number of methane $\left(\mathrm{CH}_{4}\right)$ records, number of cows and their parity, and mean methane emissions for each breed included in the present study.

\begin{tabular}{|c|c|c|c|c|c|c|c|c|}
\hline \multirow{2}{*}{ Breed } & \multirow{2}{*}{$\mathrm{n}$ data } & \multirow{2}{*}{$\begin{array}{l}\% \text { of } \\
\text { data }\end{array}$} & \multirow{2}{*}{$\mathrm{n}$ cows } & \multirow{2}{*}{$\begin{array}{l}\% \text { of } \\
\text { cows }\end{array}$} & \multicolumn{3}{|c|}{ Parity (n cows) } & \multirow{2}{*}{$\begin{array}{c}\mathrm{CH}_{4}(\mathrm{~g} / \mathrm{d}) \\
\text { mean } \pm \mathrm{SD}\end{array}$} \\
\hline & & & & & 1 & 2 & $>2$ & \\
\hline $\mathrm{HO}$ & 891 & 82 & 222 & 74 & 63 & 84 & 75 & $415 \pm 107$ \\
\hline JER & 67 & 6 & 10 & 3 & 4 & 2 & 4 & $342 \pm 42$ \\
\hline BS & 78 & 7 & 39 & 13 & 7 & 7 & 25 & $458 \pm 69$ \\
\hline $\mathrm{RH}$ & 21 & 2 & 8 & 3 & 1 & 5 & 3 & $427 \pm 74$ \\
\hline SRX & 14 & 1 & 7 & 2.5 & I & 2 & 5 & $348 \pm 37$ \\
\hline NR & 9 & 1 & 6 & 2 & 1 & 2 & 4 & $423 \pm 79$ \\
\hline HOX & 9 & 1 & 7 & 2.5 & 3 & 2 & 2 & $427 \pm 54$ \\
\hline
\end{tabular}

HO: Holstein; JER: Jersey; BS: Brown Swiss; RH: Red Holstein; SRX: Swedish Red crossed; NR: Norwegian red; HOX: Holstein crossed.

Table 3 : Number of methane $\left(\mathrm{CH}_{4}\right)$ records included in the reference dataset with regard to stage of lactation (DIM), country of origin and the method used to measure enteric $\mathrm{CH}_{4}$ emissions

\begin{tabular}{|c|ccccccc|c|c|c|}
\hline Class of DIM & BE & IE & UK & FR & DK & CH & D & Total $\mathrm{SF}_{6}$ & Total RC & TOTAL \\
\hline $0-20$ & - & - & - & - & - & 6 & - & - & 6 & $\mathbf{6}$ \\
$21-40$ & 4 & - & - & - & - & 24 & 63 & 4 & 87 & $\mathbf{9 1}$ \\
$41-60$ & 8 & 6 & - & - & - & 4 & 7 & 14 & 11 & $\mathbf{2 5}$ \\
$61-80$ & 15 & 17 & - & - & - & 4 & - & 32 & 4 & $\mathbf{3 6}$ \\
$81-100$ & 15 & 30 & - & - & - & 31 & 9 & 45 & 40 & $\mathbf{8 5}$ \\
$101-120$ & 20 & 29 & - & - & - & 30 & 56 & 49 & 86 & $\mathbf{1 3 5}$ \\
$121-140$ & 33 & 32 & - & 3 & - & 10 & - & 65 & 13 & $\mathbf{7 8}$ \\
$141-160$ & 12 & 33 & - & 11 & 3 & 4 & 2 & 45 & 20 & $\mathbf{6 5}$ \\
$161-180$ & 25 & 40 & 6 & 15 & 12 & 2 & 8 & 65 & 43 & $\mathbf{1 0 8}$ \\
$181-200$ & 14 & 25 & 16 & 13 & 16 & 4 & 2 & 39 & 51 & $\mathbf{9 0}$ \\
$201-220$ & 12 & 26 & - & 18 & 12 & - & 2 & 38 & 32 & $\mathbf{7 0}$ \\
$221-240$ & 38 & 18 & 2 & 16 & 17 & 2 & 2 & 56 & 39 & $\mathbf{9 5}$ \\
$241-260$ & 26 & 5 & - & 5 & 32 & 6 & 2 & 31 & 45 & $\mathbf{7 6}$
\end{tabular}




\begin{tabular}{|c|ccccccc|c|c|c|}
$261-280$ & 19 & - & - & - & 21 & 2 & 2 & 19 & 25 & $\mathbf{4 4}$ \\
$281-300$ & 5 & - & - & - & 14 & 4 & 31 & 5 & 49 & $\mathbf{5 4}$ \\
$301-320$ & 3 & - & - & - & 2 & - & 21 & 3 & 23 & $\mathbf{2 6}$ \\
$321-340$ & 3 & - & - & - & - & 2 & - & 3 & 2 & $\mathbf{5}$ \\
\hline TOTAL & $\mathbf{2 5 2}$ & $\mathbf{2 6 1}$ & $\mathbf{2 4}$ & $\mathbf{8 1}$ & $\mathbf{1 2 9}$ & $\mathbf{1 3 5}$ & $\mathbf{2 0 7}$ & $\mathbf{5 1 3}$ & $\mathbf{5 7 6}$ & $\mathbf{1 , 0 8 9}$ \\
\hline
\end{tabular}

DIM: Days In Milk, RC: Respiration Chamber, Belgium (BE), Ireland (IE), United-Kingdom (UK), France (FR), Denmark (DK), Switzerland (CH) and Germany (D).

Table 4: Versions of calibration equations developed based on milk FT-MIR spectra modified with Legendre Polynomials, with or without added phenotypic factors as explanatory variables.

\begin{tabular}{lcc}
\hline Model & $\begin{array}{c}\text { Number of } \\
\text { explanatory variables }\end{array}$ & Name \\
\hline Modified spectra & 867 & MS \\
Modified spectra + milk yield & 868 & MSMY \\
Modified spectra + parity & 868 & MSP \\
Modified spectra + breed & 873 & MSB \\
Modified spectra + milk yield + parity & 869 & MSMYP \\
Modified spectra + milk yield + breed & 874 & MSMYB \\
Modified spectra + parity + breed & 874 & MSPB \\
Modified spectra + milk yield + parity + breed & 875 & MSMYPB \\
\hline Modified spectra: milk FT-MIR spectra regressed by the modified Legendre Polynomials to take into account & &
\end{tabular}

Table 5: Calibration statistics for each developed calibration equation $(n=1,089)$.

\begin{tabular}{|c|c|c|c|c|c|c|c|c|c|c|c|c|}
\hline Model & $\begin{array}{c}\mathrm{n} \\
\text { facto } \\
\mathrm{rs}\end{array}$ & $\begin{array}{c}\mathrm{R}^{2} \\
\mathrm{c}\end{array}$ & $\begin{array}{c}\mathrm{R}^{2} \mathrm{c} \\
\mathrm{V}\end{array}$ & $\begin{array}{c}\text { SEC } \\
\text { (g/da } \\
\mathrm{y})\end{array}$ & $\begin{array}{c}\text { SEC } \\
\text { V } \\
(\mathrm{g} / \mathrm{da} \\
\mathrm{y})\end{array}$ & $\begin{array}{l}\mathrm{RP} \\
\mathrm{Ec} \\
(\%)\end{array}$ & $\begin{array}{c}\text { RPE } \\
\text { cv } \\
(\%)\end{array}$ & $\begin{array}{l}\mathrm{R}^{2} \text { for } \\
\mathrm{CCD} \\
\mathrm{EV} \\
\text { Mean } \\
\pm \mathrm{SD}\end{array}$ & $\begin{array}{c}\text { RMS } \\
\text { EP } \\
\text { for } \\
\text { CCD } \\
\text { EV } \\
\text { Mean } \\
\text { (g/da } \\
\text { y) } \pm \\
\text { SD }\end{array}$ & AIC & BIC & $\begin{array}{c}\mathrm{CC} \\
\mathrm{C}\end{array}$ \\
\hline MS & 14 & 0.6 & 0.6 & 58 & 61 & 13. & 14.9 & 0.55 & $70 \pm$ & 12,0 & 12,1 & 0.7 \\
\hline
\end{tabular}




\begin{tabular}{|c|c|c|c|c|c|c|c|c|c|c|c|c|}
\hline & & 8 & 4 & & & 9 & & $\begin{array}{c} \pm \\
0.07\end{array}$ & 4.5 & 55 & 35 & 9 \\
\hline MSMY & 14 & $\begin{array}{c}0.6 \\
9\end{array}$ & $\begin{array}{c}0.6 \\
5\end{array}$ & 57 & 60 & $\begin{array}{c}13 . \\
6\end{array}$ & 14.7 & $\begin{array}{c}0.57 \\
\pm \\
0.07\end{array}$ & $\begin{array}{c}70 \pm \\
4.5\end{array}$ & $\begin{array}{c}11,9 \\
97\end{array}$ & $\begin{array}{c}12,0 \\
77\end{array}$ & $\begin{array}{c}0.7 \\
9\end{array}$ \\
\hline MSP & 14 & $\begin{array}{c}0.7 \\
0\end{array}$ & $\begin{array}{c}0.6 \\
5\end{array}$ & 56 & 60 & $\begin{array}{c}13 . \\
6\end{array}$ & 14.8 & $\begin{array}{c}0.57 \\
\pm \\
0.07\end{array}$ & $\begin{array}{c}68 \pm \\
4.2\end{array}$ & $\begin{array}{c}11,9 \\
90\end{array}$ & $\begin{array}{c}12,0 \\
70\end{array}$ & $\begin{array}{c}0.7 \\
9\end{array}$ \\
\hline MSB & 14 & $\begin{array}{c}0.7 \\
0\end{array}$ & $\begin{array}{c}0.6 \\
6\end{array}$ & 56 & 60 & $\begin{array}{c}13 . \\
5\end{array}$ & 14.5 & $\begin{array}{c}0.57 \\
\pm \\
0.06\end{array}$ & $\begin{array}{c}68 \pm \\
4.4\end{array}$ & $\begin{array}{c}11,9 \\
89\end{array}$ & $\begin{array}{c}12,0 \\
69\end{array}$ & $\begin{array}{c}0.8 \\
0\end{array}$ \\
\hline $\begin{array}{c}\text { MSMY } \\
\text { P }\end{array}$ & 14 & $\begin{array}{c}0.7 \\
0\end{array}$ & $\begin{array}{c}0.6 \\
6\end{array}$ & 56 & 60 & $\begin{array}{c}13 . \\
4\end{array}$ & 14.5 & $\begin{array}{c}0.58 \\
\pm \\
0.07\end{array}$ & $\begin{array}{c}67 \pm \\
4.1\end{array}$ & $\begin{array}{c}11,9 \\
62\end{array}$ & $\begin{array}{c}12,0 \\
42\end{array}$ & $\begin{array}{c}0.8 \\
0\end{array}$ \\
\hline $\begin{array}{c}\text { MSMY } \\
\text { B }\end{array}$ & 15 & $\begin{array}{c}0.7 \\
2\end{array}$ & $\begin{array}{c}0.6 \\
8\end{array}$ & 54 & 58 & $\begin{array}{c}13 . \\
0\end{array}$ & 14.3 & $\begin{array}{c}0.60 \\
\pm \\
0.06\end{array}$ & $\begin{array}{c}66 \pm \\
4.2\end{array}$ & $\begin{array}{c}11,8 \\
97\end{array}$ & $\begin{array}{c}11,9 \\
82\end{array}$ & $\begin{array}{c}0.8 \\
1\end{array}$ \\
\hline MSPB & 14 & $\begin{array}{c}0.7 \\
1\end{array}$ & $\begin{array}{c}0.6 \\
7\end{array}$ & 55 & 59 & $\begin{array}{c}13 . \\
2\end{array}$ & 14.5 & $\begin{array}{c}0.59 \\
\pm \\
0.06\end{array}$ & $\begin{array}{c}66 \pm \\
4.1\end{array}$ & $\begin{array}{c}11,9 \\
27\end{array}$ & $\begin{array}{c}12,0 \\
07\end{array}$ & $\begin{array}{c}0.8 \\
1\end{array}$ \\
\hline $\begin{array}{c}\text { MSMY } \\
\text { PB }\end{array}$ & 15 & $\begin{array}{c}0.7 \\
3\end{array}$ & $\begin{array}{c}0.6 \\
8\end{array}$ & 53 & 57 & $\begin{array}{c}12 . \\
8\end{array}$ & 14.1 & $\begin{array}{c}0.60 \\
\pm \\
0.06\end{array}$ & $\begin{array}{c}65 \pm \\
4.1\end{array}$ & $\begin{array}{c}11,8 \\
69 \\
\end{array}$ & $\begin{array}{c}11,9 \\
54 \\
\end{array}$ & $\begin{array}{c}0.8 \\
1 \\
\end{array}$ \\
\hline
\end{tabular}

MS: Modified spectra, MSMY: Modified spectra + milk yield, MSP: Modified spectra + parity, MSB: Modified spectra + breed, MSMYP: Modified spectra + milk yield + parity, MSMYB: Modified spectra + milk yield + breed, MSPB: Modified spectra + parity + breed, MSMYPB: Modified spectra + milk yield + parity + breed, SEC: Standard Error of Calibration, SECV: Standard Error of Cross Validation, RPEc: relative predictive error of calibration; RPEcv: relative predictive error of cross validation; $\mathrm{R}^{2}$ for CCDEV: cow and country dependent external validation coefficient of determination, RMSEP forof CCDEV: Root Mean Square Error of prediction for cow and country dependent external validation, SD: standard deviation, AIC: Akaike information criterion, BIC: Bayesian information criterion; CCC: concordance correlation coefficient.

Table 6: Effect of days in milk (DIM), daily milk yield, parity, country and breed on the residuals of each calibration model developed

\begin{tabular}{|c|c|c|c|c|c|}
\hline Model & DIM & Milk Yield & Parity & Country & Breed \\
\hline MS & NS & $* * *$ & $* * *$ & $* * *$ & $* * *$ \\
\hline MSMY & NS & $*$ & $* * *$ & $* * *$ & $* * *$ \\
\hline MSP & NS & $* * *$ & NS & $* *$ & $* * *$ \\
\hline MSB & NS & $* * *$ & $* * *$ & NS & $* * *$ \\
\hline MSMYP & NS & NS & NS & $* * *$ & $* * *$ \\
\hline MSMYB & NS & NS & $* * *$ & NS & $* *$ \\
\hline MSPB & NS & $* * *$ & NS & NS & $*$ \\
\hline MSMYPB & NS & NS & NS & NS & $*$ \\
\hline
\end{tabular}

DIM: Days in milk, MS: Modified spectra, MSMY: Modified spectra + milk yield, MSP: Modified spectra + parity, MSB:

Modified spectra + breed, MSMYP: Modified spectra + milk yield + parity, MSMYB: Modified spectra + milk yield + breed, MSPB: Modified spectra + parity + breed, MSMYPB: Modified spectra + milk yield + parity + breed, DIM: Days In Milk, NS: Non Significant, $* \mathrm{P}<0.05$, ** $\mathrm{P}<0.01$, *** $\mathrm{P}<0.001$ 
Table 7: Cow and breed dependent external validation statistics for developed calibration models for Holstein cows

\begin{tabular}{|c|c|c|c|c|}
\hline \multirow{2}{*}{ Model } & \multicolumn{2}{|c|}{$\mathrm{R}^{2}$ for CBDEV } & \multicolumn{2}{c|}{ RMSEP for CBDEV } \\
\cline { 2 - 5 } & Mean \pm SD & Min - Max & Mean \pm SD & Min - Max \\
\hline MS & $0.57 \pm 0.08$ & $0.38-0.77$ & $71 \pm 5.0$ & $57-87$ \\
\hline MSMY & $0.59 \pm 0.08$ & $0.36-0.77$ & $71 \pm 5.0$ & $57-87$ \\
\hline MSP & $0.59 \pm 0.08$ & $0.36-0.79$ & $69 \pm 4.9$ & $56-82$ \\
\hline MSMYP & $0.60 \pm 0.08$ & $0.36-0.78$ & $68 \pm 4.7$ & $54-82$ \\
\hline
\end{tabular}

MS: Modified spectra, MSMY: Modified spectra + milk yield, MSP: Modified spectra + parity, MSMYP: Modified spectra + milk yield + parity, $\mathrm{R}^{2}$ for CBDEV: cow and breed dependent external validation coefficient of determination, RMSEP for CBDEV: Root Mean Square Error of prediction for cow and breed dependent external validation 